the present, and to use the shower-bath occasionally.

16. There is not the slightest motion of the head perceptible. He complains of faintness, and occasionally an "inward trembling;" the bowels are regular, and still dark, from the effects of the iron; his tong te is rather furred in the morning. Ordered a common dyspeptic pill, three times a day.

26. Is quite well. Has becn at work since last report, and has had no return of the complaint.

May 3. Continues quite well.

The above case is extracted verbatim from my case-book. The quantity of the Carbonate taken from March 16th to April 12th amounts to thirty-two ounces five drachms. I was only obliged to omit it once during that time.

Stowmarket, Suffolk, May 3, 1835.

ON THE HYPOTAESIS OF THE

\section{VASCULARITY OF THE TEETH.}

\section{To the Editor of THE LanceT.}

Srn - The insertion of the following remarks on the above subject, with reference to dental surgery, will afford me much gratification, and will, I trust be acceptable to your junior medical readers, as briefly detailing the opinions and discoveries of the great anatomical authorities on the teeth. I beg to preface the paper with the remark from Magendie's lectures, that "By adhering closely to facts, by taking nothing for granted which we are unable to prove, and, above all, by employing our senses in the investigation of the physiological conditions of the different tissues, we have been able to understand several points of physiology which were before unintelligible, or were obscured by vain and imaginary theories." I am, Sir, your obedient servant,

William Prckering, Dentist.

21, Vere Street, Cavendish Square, April 28th, 1835.

It is a subject of general regret and complaint with the profession, that the practice of dental surgery is yet so little in harmony with the present advanced state of anatomical and physiological science, but still remains the almost undisputed stronghold of ignorance and empiricism. In vain for it have anatomy and physiology unfolded their treasures; in vain have such men as Hunter, Cuvier, Sir C. Bell, Blain- ville, Lawrence, Geoffroy St. - Hilaire, Samuel Cooper, and others, published their labours and discoveries. Dentists seem totally unconscious of their existence, and dentistry still remains a by-word for jesters. There are, undoubtedly, many honomable exceptions anongst them,men of deserved repute, who would wish to see an altered state of things.

On a correct idea of the anatomy of the teeth and their connexions, alone, can a successful treatment of their diseases be established. It is necessary to be conver: sant with the membranes, and the formation of the pulp or rudiment, as they exist in foetal life. Authors differ as to the precise period at which the rudiments may be discoverch. Dr. Blake, in his excellent treatise on the teeth, states that he perceived them as early as four months after conception. Monsieur Serres, a French anatomist, mentions three months; and another author,* whose singular assertions I shall have occasion to notice hereafter, assures us that he has perceived them at two months after conception; that is to say, at a period when not only the or: garization of the jaws themselves, but that of any part of the system, has scarcely proceeded, so far as our senses can determine, beyond a confused and gelatinous mass! I never was myself, however, able to see anything of the rudiments of the teeth hefore the fourth or fifth month, at which period the twenty deciduous, and the four anterior, permanent molares, may be seen in a groove on the jaw-bone. "These rudiments," says Dr. Blake, "are so intimately connected with the gum, that they seemed derived from it, and came with it, when torn from the groove in the jaw, leaving behind the vessels and nerves with which they had been in contact." The pulp, or rudiment itself, appears to be a gelatinous substance, having a double involucre, which Cuvier has ingeniously compared to the double folding of a nightcap. The following sketch will convey an idea of the pulp, as it is found in foetal life, previous to the deposition of the enamel and ivory of the tooth.

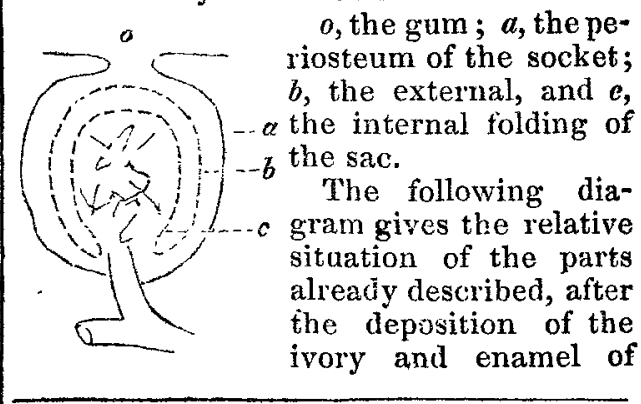

* T. Bell's Anatomy, Physiology, and Diseases of the Teeth, 8vo, London. 
the tooth; and when completely out of points of resenblance between them is a the gum:- $o$ gum, $e$ enamel, $b$ the irory. point which must be granted by every The dotted lines repre- ons who is in the least conversant with sent, as in the first dlia- osteogony. One might, indeed, be equally gram, the membranes of justified in asserting the vascularity of the the pulp; the tooth is bony deposition which takes place in the perceived to be depo-l coats of arteries and other parts of aged

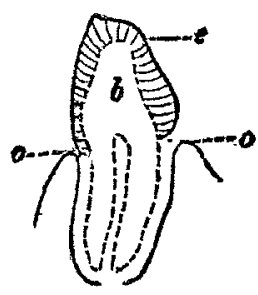
sited between the internal and external folding of the sac. It is secreted by the pulp contained within, which at this time becomes highly vascular. The enamel is completely formed before the issue of the tooth out of the gum, and is supposed to be seereted by the internal surface of the periosteum of the socket $(a)$. It is a crystallized and inorganic substance, which, when once destroyed, is never renewed. Bichat is the only anatomist that I know of who ever supposed it to be otherwise; and his opinion is founded on the disagreeable sensation called " tooth-edge," produced by the action of acids. But it is well known that this only takes place on the trituration surfaces of the teeth $(a)$; or where a portion of the enamel has been destroyed (b), so as to expose to the effects of external agency the peridental membrane.
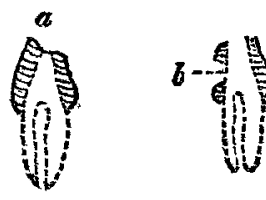

Having thus briefly described the varions membranes of the pulp, I will now come to the more immediate subject of this paper. "The question whether the teeth are vascular," says Samnel Cooper, to whose excellent commentaries on $\mathrm{Ma}$ son Good's Study of Medicine I refer the reader for further detail, " is extremely curious and interesting; ard so unnatural is the idea of an harmonious connexion between dead and living substances, that the common opinion of the teeth being furnighed with vessels and nerves is not at all surprising." If, however, we apply to this prima-facie view of the subject the test of rigorous observation and experience, we shall be induced, with Mr. S. Cooper, and other high authorities, to form a different opinion. With reference to the arguments adduced by Fox and others in support of the vascularity of the teeth, they must appear, on examination, to be but little in harmony with the present advanced state of anatomical science.

The manner in which the ivory of the tooth is secreted from the pulp, within the foldings of the sac, does not countenance in the least the idea of its being vascular. It has been vainly attempted to adcluce arguments from its apparent similitude to bone; but that there are no essential subjects, and which, according to Sir Charles Bell, "is merely the deposit of earthy matter, without organic structure." Cuvier, in describing the formation of the teeth, is remarkably explicit:-"We will call the soft and central part "the pulp" (noyau pulpeu) of the tooth; which, though it fills exactly all its cavity, is not organicly connected with the ivory ; and neither its vessels nor its neves are seen to traverse its membranes, to enter into the hard part of the tooth : in a word, the pulp is contained in the tooth, without adhering to it, but is attached to the bottom of the alveoli by its vessels and nerves. Nor do any vessels or nerves pass from the alveoli inco the roots of the tooth; so that the roots, abstraction made of the pulp, and its continuation through their centre, may be considered to be implanted in the alveoli in the same way as a nail is mechanically retained in a piece of board." (Gomphosis.)

With reference to the experiments made on the teeth with madder, it is well known that if that substance be given to a young animal at the time of the formation of the teeth, that portion of the tooth which is forming during its administration will become tinged. This colour once imparted to the teeth is never removed, as is the case with hones under similar circumstances. The foregoing amounts to a proof of the total absence in the teeth of absorbents and incerstitial action. The argument deduced from a yellow tinge being communicated to the tecth by the pulp in the case of jaundice, only proves that some persons can mistake porosity for vascularity.

One may be at a loss to guess what could have induced some authors to infer that caries or decay of the tooth is the result of ulceration, in the face of facts which prove that the phenomena in question also take place in artificial teeth, and in teeth which have been boiled, or kept so long in a draswer as not to admit of the suspicion of their being alive. On this question, I cannot refraik from quoting an extract from Sir Charles Bell's excellent lectures on the teeth, which will, I trust, be conclusive. "Again; the tooth does not change when the bones change. The bones become soft in mollities ossium, but there is no change in the teeth; neither is there any change in them during disease of the joints, unless (I beg you to remem- 
ber this circumstance) the tooth is forming at the period when a patient is labouring under rickets, or a diseased constitution; and then you find remarkable defects in the teeth. Again, is a tooth sensible? No. We camnot inagine the existence of sensibility in a part which is not vascular. But although the tooth is not sensible, it is guarded against danger; for I was particular to notice that sensibility was given to a part as a guard; and so is there a similar provision here. The sensibility resides in the membranes, brought into play by the nerve of the tooth, and not in the tooth itself. Analogous to this is the case of the hoof, which, in one sense, is not insensible; yet every vibration of the hoof, every impulse given to it, conveys a sensation to the horse. When the crust or hoof is peeled off, we find certain processes in the foot-vascular extremities and nerves. So that the hoof, though not sensible itself, receives an impulse or a vibration which is conveyed to the end of the nerve, and the horse feels the ground just as you feel what is between the teeth."

I should have hardly thought it necessary to undertake a serious refutation of the opinion of the vascularity of the teeth, had not an author of our own day attempted, in a work entitled "Anatomy, Physiology, and Diseases of the Teeth," to establish on this erroneous and obsolete theory the whole practice of Dental Surgery. Had the author here alluded to confined its application to his own private practice, none but his patients would have reason to complain; but as a writer to whose opinions the situation of lecturer on the teeth, at a celebrated hospital, tends to give weight and authority, it is incumbent on me to warn the young student against the danger attending the application of his views. A few quotations from the work in question will suffice to give an idea of the peremptory style in which the author treats this subject. Arguing on the vascularity of the teeth, he says : "I have, however, in many instances, on pur. posely breaking a tooth, immediately after extraction, where the pain and inflammation had been severe, found distinct red patches in the very substance of the bone" In another no less extraordinary passage he adds, "The question, however, does not rest upon doubtful experinent. A case which occurred to me some years since, the preparation of which is now in my possession, appears to me satisfactorily to prove the presence of absorbents in the teeth. It was, in fact, an instance of true abscess in the bone of a twoth. Inflamma. tion hall existed for a considerable time, and, after extraction, on sawing the tooth through, for the purpose of ascertaining the state of the internal structure, I found a cavity formed in the very substance of the tooth, communicating with the natural cavity, and filled with pus." The above passages are so ininical to sound sense as to require no further notice.

The author's opinions respecting the liability of the ivory of the teeth to disease, inflammation, mortification, suppuration, and his adoption of the term "gangrene" to signify carıes, or chemical decay, are equally unsupported; but having once adopted the hypothesis of the vascularity of the teeth, he is led to infer their liability to all the pathological contingencies peculiar to vascular tissues. And, to preserve a lamentable consistency, we find the following remarkable avowal: "I have dwelt the longer on this subject (the vascularity of the teeth), from a persuasion of its practical importance; for: unless this opinion be correct, my ideas on the diseases of these organs are wholly fallacious, and the mode of practice which I shall have to recommend is founded altogether on false data."

The ivory of the teeth not being vascular, but merely a deposit of bony matter, without organic structure, what, then, is caries or decay? Nothing but chemical decomposition, produced by the various well-known acids found at one time or other in the mouth, to which may perhaps be added the sulpho-cyanic, lately discovered in the saliva by Tiedemann and Gmelin. The sudden transitions of temperature may also be considered as a sufficient cause. The tooth is composed of the enamel and the ivory, two bodies of unequal densities. They will, consequently, expand in different proportions, under the influence of caloric. It may be supposed that the enamel not being able to follow the expansion of the ivory, cracks in different places. And, in fact, I have observed in every incipient caries, at least one crack or fissure. Now, it is perfectly evident that these cracks are sufficient to give passage to the various acids by which the phosphate of lime of the ivory may be affected, viz., the oxalic, tartaric, succinic, and sulphuric. In confirmation of the abore, I may observe, everybody has had occasion to observe, that a small hole in the enamel is in most cases but the external sign of a very large cavity, for the progress of decomposition always pro. ceeds under the enamel.

Will anybody contend that the question alreatly so much dilated on in this paper is not of the greatest inportance with reference to the practice of dental surgery? If the teeth were vascular bodies, it must necessarily follow, that whenever a tooth is once affected by ulceration or 
gangrene, extraction is the only remedy.' had a tooth excised by the individual And, in fact, the supporters of this theory already alluded to. The inquiries, howhave advocated that operation to a most ever, which 1 have made to anthentifearful extent. It is convenient, in one cate the case, learl roe to think that the respect, as it confines the practice of den- fatal event was not caused merely by the tal surgery to mere tooth-drawing. Were excision of the tooth, but by the introducthe teeth vascular bodies, and decay the tion immediately after the operation of a result of ulceration, the operations of stylet, or gold pivot, which was either too filing and stopping would be impossible, long, and went beyong the fang, or was "for who has ever heard," says Mr. Sa- introduced without the necessary precaumuel Cooper, " of filing or stopping with tion of previously cauterizing the nerve, metal, as it is practised on the teeth, an as it is always practised. In confirmation irritable ulcer?"

It was not my intention in this paper to enter largely on dental surgery, but I cannot conclude without saying a word or two on an operation which, in my opinion, does not deserve all the obloquy which has been thrown upon it: I allude to the operation of excision. Not that I agree to all the pretensions of the individual who is stated to have introduced it into this country; but, making allowances for the exaggerations of interested empiricism, I certainly believe that it may be recommended in some cases with advantage. As the operation seems to have become almost obsolete, a short description of it will, perhaps, be acceptable. "It is performed with a pair of forceps accurately fitted to the necks of the teeth, having fine well-tempered cutting edges; these edges must be carefully applied on the neck of the tooth as close to the gums as possible, taking care to keep the edges parallel to the edges of the gums, which are to be depressed a little with the inferior surface of the blades of the forceps, so as to bring the cutting edges fairly beneath the enamel. Then with a gradual application of pressure on the handles of the forceps, the tooth is in an instant snapped off at the neck." When performed on the front teeth (the only ones in which I would recommend the operation, as they have only one fang), the following curious fact takes place. In the first instance, the portion of the pulp remaining in the fang immediately contracts within it, and a small quantity of blood is seen to ooze out; it soon coagulates, and a new membrane forms itself over the remaining part of the pulp, as if to defend it from the effects of external agency. Soon after, the pulp assumes a new and increased secretory action, and in the course of a few weeks the exposed cavity of the stump becomes plugged up with bony matter. When the operation has been carefully pertormerl, the souml stunu may be turned to excellent account, as forming a good basis for artificial teeth.

But as an objection to the operation of excision, a case is quoted of a lady whr died at Eltham, of trismus, after having of the above view of the subject, a case is quoted by Aridral of a nun, who, in despite of her renuniciation of worldly attractions, had a deficiency in her mouth supplied by a pivot tooth. Owing to the pivot exceeding the length of the farg, and the non-cauterization of the nerve, the unfortunate patient was seized with trismus and died.

\section{E C T U R E}

DELIVERED AT THB

\section{NORTH LONDON HOSPITAL, B Y}

\section{A. T. THOMSON, M.D.,}

Physician to the Hospital, and Professor of Materia Medıca in the University of London.

DROPSY AND ITS VARIETIES.

Gentremen, - I have at this time four cases of dropsy under treatment in the hospital, a circumstance which affords me a fair opportunity of demonstrating to you the varieties of form which these serous effusions display, and pointing out how far those varieties contribute to modify the treatment.

CASE 1. Ascites.-The first of these cases is that of Kendrick, who was discharged apparently cured on the 8th of January ; on the 25th of March he returned with renewed symptoms of ascites, the abdomen being nearly as large, although less tense, and the fluctuation as distinct, as when he first entered the hospital. His gerseral health and appearance seemed rather better than when he left the hospital, and there was no oedema in any part of the body. He scrted that the aboiomen began to enlarge ahout ten days after he went out of the hospital, and had gradually increased both in size and tension, bnt that in every other respect he felt in sood health. He had lived temperatery, and ould not account for the return of the disease. You will recollect that I stated 